\title{
Relationships Between Biochemical Markers of Hyperandrogenism and Metabolic Parameters in Women with Polycystic Ovary Syndrome: A Systematic Review and Meta-Analysis
}

Authors

Mina Amiri', Fahimeh Ramezani Tehrani ${ }^{1}$, Razieh Bidhendi-Yarandi1,2, Samira Behboudi-Gandevani ${ }^{1}$, Fereidoun Azizi ${ }^{3}$, Enrico Carmina ${ }^{4}$

\section{Affiliations}

1 Reproductive Endocrinology Research Center, Research Institute for Endocrine Sciences, Shahid Beheshti University of Medical Sciences, Tehran, Iran

2 Department of Epidemiology and Biostatistics, School of Public Health, Tehran University of Medical Sciences, Tehran, Iran

3 Endocrine Research Center, Shahid Beheshti University of Medical Sciences, Tehran, Iran

4 Endocrinology Unit, Department of Health Sciences and Mother and Child Care, University of Palermo, Palermo, Italy

Key words

meta-analysis, polycystic ovary syndrome, FerrimanGallwey score, metabolic disorder, insulin resistance

received 19.08 .2018

accepted 20.11.2018

Bibliography

DOI https://doi.org/10.1055/a-0806-8281

Horm Metab Res 2019; 51: 22-34

(c) Georg Thieme Verlag KG Stuttgart · New York ISSN 0018-5043

Correspondence

Fahimeh Ramezani Tehrani, MD.

Professor of Obstetrics and Gynecology

Research Institute for Endocrine Sciences

No 24, Parvane Street, Yaman Street

Velenjak

Tehran

Iran

Tel.: + 98/224/32 500, Fax: + 98/224/16 264

ramezani@endocrine.ac.ir, framezan@post.harvard.edu

丹upplementary material for this article is available online at http://www.thieme-connect.de/products.

\section{ABSTRACT}

While several studies have documented an increased risk of metabolic disorders in patients with polycystic ovary syndrome (PCOS), associations between androgenic and metabolic parameters in these patients are unclear. We aimed to investigate the relationships between biochemical markers of hyperandrogenism (HA) and metabolic parameters in women with PCOS. In this systematic review and meta-analysis, a literature search was performed in the PubMed, Scopus, Google Scholar, ScienceDirect, and Web of Science from 2000 to 2018 for assessing androgenic and metabolic parameters in PCOS patients. To assess the relationships between androgenic and metabolic parameters, meta-regression analysis was used. A total number of 33 studies involving 9905 patients with PCOS were included in this analysis. The associations of total testosterone ( $\mathrm{tT}$ ) with metabolic parameters were not significant; after adjustment for age and BMI, we detected associations of this androgen with low-density lipoproteins cholesterol (LDL-C) $(\beta=0.006$; $95 \%$ $\mathrm{Cl}$ : 0.002, 0.01), high-density lipoproteins cholesterol (HDL-C) $(\beta=-0.009 ; 95 \% \mathrm{Cl}:-0.02,-0.001)$, and systolic blood pressure (SBP) $(\beta=-0.01 ; 95 \% \mathrm{Cl}:-0.03,-0.00)$. We observed a positive significant association between free testosterone ( $\mathrm{fT}$ ) and fasting insulin ( $\beta=0.49 ; 95 \% \mathrm{Cl}: 0.05,0.91)$; this association remained significant after adjustment for confounders. We also detected a reverse association between $\mathrm{fT}$ and HDL-C $(\beta=-0.41 ; 95 \% \mathrm{Cl}:-0.70,-0.12)$. There was a positive significant association between A4 and TG $(\beta=0.02 ; 95 \% \mathrm{Cl}: 0.00$, 0.04 ) after adjustment for PCOS diagnosis criteria. We also found significant negative associations between A4, TC, and LDL-C. Dehydroepiandrosterone sulfate (DHEAS) had a positive association with $\operatorname{LDL}-\mathrm{C}(\beta=0.02 ; 95 \% \mathrm{Cl}: 0.001,0.03)$ and a reverse significant association with $\mathrm{HDL}-\mathrm{C}(\beta=-0.03$; $95 \% \mathrm{Cl}$ : $-0.06,-0.001)$. This meta-analysis confirmed the associations of some androgenic and metabolic parameters, indicating that measurement of these parameters may be useful for predicting metabolic risk in PCOS patients. 


\section{Introduction}

Polycystic ovary syndrome (PCOS) is a common endocrine and metabolic disorder characterized by chronic anovulation, clinical and/ or biochemical hyperandrogenism (HA), and/or polycystic ovaries [1]. The Androgen Excess-PCOS (AE-PCOS) Society Task Force considered $\mathrm{HA}$ as an essential criteria for diagnosing PCOS [2]. High blood levels of several androgens including serum total testosterone ( $\mathrm{tT}$ ), free testosterone (fT), androstenedione (A4), dehydroepiandrosterone sulfate (DHEAS), and calculated free androgen index (FAI) may be used to detect biochemical HA [3].

It is well-documented that PCOS is associated with increased risk of metabolic disorders $[1,4]$, which may be attributed to HA, obesity, dyslipidemia, impaired glucose tolerance, insulin resistance, and/or type 2 diabetes mellitus (T2DM) [5, 6]. In particular, high insulin levels secondary to insulin resistance may participate to the increased androgen production of women with PCOS, which can aggravate clinical symptoms of $\mathrm{HA}$ [7]. Biochemical markers of HA may be correlated with fasting blood sugar (FBS), fasting insulin, insulin resistance, lipids levels and blood pressure (BP) [5, 7]. However, a limited number of studies have investigated the relationships between $\mathrm{HA}$ and metabolic parameters in women with PCOS and different results have been reported $[7,8]$. In addition, the role of androgens on the development of hypertension in women is controversial [9], especially in patients with obesity and insulin resistance [10].

In this systematic review and meta-analysis, we aimed to re-evaluate, in women with PCOS, the relationships between biochemical parameters of HA and metabolic findings. Because commercial assays of androgens, and in particular of tT and fT have been criticized for being inaccurate, we conducted a sub-analysis trying to differentiate the results on the basis of the assay used for androgen measurement. In fact, it has been reported that many methods for measuring androgens have low sensitivity for female $\mathrm{HA}$ and that only some methods including mass spectrometry/liquid chromatograph (LC/MS) may produce accurate and reliable assessment of androgen circulating levels [11].

\section{Materials and Methods}

This systematic review and meta-analysis was performed according to the Preferred Reporting Items for Systematic Reviews and Meta-Analyses (PRISMA) [12] to investigate the relationships between androgenic, and metabolic parameters in women with PCOS. The study has been approved as a research project by the Research Institute for Endocrine Sciences (RIES), Shahid Beheshti University of Medical Sciences, Tehran, Iran. Registration number: IR.SBMU.RIES.RES.1394.90.

The PICO question of this study was in reproductive age women with PCOS; what are the relationships between biochemical markers of $\mathrm{HA}$ and metabolic parameters?

\section{Eligibility criteria}

We searched randomized controlled trials (RCTs), non-randomized studies (NRS), prospective or retrospective cohort studies, and case-control studies restricted to published papers in English from 2000 to 2018 . Studies were eligible if they had: (1) a study population including PCOS women, diagnosed by criteria of the Rotterdam,
National Institutes of Health (NIH) or the Androgen Excess Society (AES); (2) assessed at least one metabolic parameter, including FBS, fasting insulin, Homeostatic Model Assessment of Insulin Resistance (HOMA-IR), triglycerides (TG), total cholesterol (TC), low-density lipoproteins cholesterol (LDL-C), high-density lipoproteins cholesterol (HDL-C) and BP, and at least one androgenic profile, including tT, fT, A4, and DHEAS. We also excluded: (1) non-human studies, reviews, commentaries, editorials, letters, meeting abstracts, case reports, (2) studies that had a population with idiopathic hirsutism or the other types of HA, diabetes, cardiometabolic, or thyroid disorders, and (3) studies that did not provide accurate and clear data or methods. Clinical HA is identified by hirsutism, acne, and alopecia [13]. High levels of serum total testosterone (tT), free testosterone (fT), free androgen index (FAl), androstenedione (A4) and dehydroepiandrosterone sulfate (DHEAS) also indicate biochemical HA [3].

\section{Search strategy}

Before initiation of the study, we conducted the search strategy with the assistance of a professional healthcare librarian. All authors performed searches separately. PubMed, Scopus, Google Scholar, ScienceDirect, and Web of Science were searched for studies documented from 2000 to May 2018 assessing androgenic and metabolic parameters in patients with PCOS, using the following terms: ["polycystic ovary syndrome" OR "polycystic ovary” AND “hyperandrogenism” OR "androgen” OR “hormone”]; ["polycystic ovary syndrome” OR “polycystic ovary” AND “metabolic” OR “insulin” OR “carbohydrate"]. We also identified additional studies through a manual search of the bibliographic references of relevant articles and existing reviews. Search strategy was almost similar for all databases. We also searched databases using free-text terms synonyms.

\section{Study selection}

In the initial screening stage, investigators independently reviewed the titles, abstracts, and keywords to exclude studies that clearly did not fulfill inclusion criteria. In the second step, they independently read the full text of remaining papers to identify eligible articles. Disagreements between reviewers were resolved by discussion or, if necessary, by all reviewers. Journals and authors were not blinded during study selection.

\section{Data extraction}

Data were extracted from full text articles by 2 reviewer (MA and SBG) in close consultation with the second one reviewer (FRT). For each eligible study, the following data were extracted: First author, publication date, country of study, study design, total number of patients, diagnostic criteria for PCOS, patient's characteristics including age and BMI, outcome measurements including FG score, tT (nanograms per milliliter, ng/ml), fT (pico grams per milliliter, $\mathrm{pg} / \mathrm{ml}$ ), A4 (ng/ml), DHEAS (micro grams per milliliter, $\mu \mathrm{g} / \mathrm{ml}$ ), FBS (milligrams per milliliter, or $\mathrm{mg} / \mathrm{ml}$ ), fasting insulin (micro Unit/milliliter, $\mu \mathrm{U} / \mathrm{ml})$, HOMA-IR, TG (mg/ml), TC ( $\mathrm{mg} / \mathrm{mL}), \mathrm{LDL}-\mathrm{C}(\mathrm{mg} / \mathrm{ml})$, $\mathrm{HDL}-\mathrm{C}(\mathrm{mg} / \mathrm{ml})$, SBP and DBP (millimeters of mercury, $\mathrm{mmHg}$ ). Baseline data of all studies were collected as mean and standard deviation (SD). To prevent extraction errors, a control check between the final data used in the meta-analysis and the original publications was performed by all authors. 


\section{Quality assessment}

The studies included for the meta-analysis were appraised for the quality of their methodological and result presentation. Two reviewers (MA and RBY) assessed the quality of the studies separately. They were blinded to study author, institution, and journal name. Disagreement was resolved and adjusted by the senior reviewer (FRT).

We used the modified consolidated standards of reporting trials (CONSORT) as a validated quality assessment checklist for RCTs. We also used CONSORT checklist for NRS after modification of it. For scoring of the quality of items, one point was given if the information for each item was stated in the study and 0 point if the information was not stated or was unclear. Studies with scores $\geq 70 \%$ of the highest level of CONSORT checklist were considered as high, 40-70\% as moderate, $20-40 \%$ as low and $<20 \%$ as very low quality [14].

In addition, observational studies including cohort, case-control, cross-sectional were appraised according to the NewcastleOttawa scale [15]. In this respect, 3 domains were scored for selection and comparability of study cohorts, and determination of the outcome of interest. If a study obtained $\geq 70 \%$ of the highest level of the Newcastle-Ottawa scale, it was considered as high quality, $40-70 \%$ as moderate, and 20 to $40 \%$ as low and $<20 \%$ as very low quality.

\section{Risk of bias assessment}

Risk of bias in each study included was assessed using the Cochrane collaboration's tools; these tools were designed for various methodological studies including for RCTs and observational studies (cohorts, cross-sectional, and case-control) [16]. NRS were assessed by ROBINS tool [17]. Review authors' judgments were categorized as "low risk," "high risk," and "unclear risk" of bias [16].

\section{Statistical analysis}

First, we conducted this meta-analysis to obtain the pooled effect size of androgenic parameters including tT, fT, A4 and DHEAS, and metabolic parameters including FBS, fasting insulin, HOMA-IR, TG, TC, LDL-C, HDL-C, SBP, and DBP. Heterogeneity test were assessed by l-squared and Chi-squared test. Random effect estimation method was applied for significant test result ( $p$-value $<0.05$ ) or I-squared greater than $50 \%$. Forest plots were also drawn to show pooled effect size and its relevant $95 \%$ confidence intervals ( $\mathrm{Cls})$ $[18,19]$.

To assess publication bias, Egger's [20] test were used. For significant results the trim and fill method was used to identify and correct for publication bias by adding certain study measures $[21,22]$.

Second, to estimate the observational relationships of androgenic parameters with metabolic parameters, random effect meta-regression models were fitted. The association between means of androgens and means of metabolic parameters were obtained as regression coefficients of the univariate models, without adjusting for confounding variables. Moreover, we fitted meta-regression models to investigate the associations between androgens and metabolic parameters, adjusted for age and BMI, diagnostic criteria for PCOS (Rotterdam, NIH, and AES), quality assessment (low and moderate vs. high), study design (RCT vs. Non-RCT) and, ethnic groups (Western, Middle East, Eastern, African) and methods of hormonal assay (Chemi/electrochemi, radioimmunoassay, Enzyme, unknown). Bubble plots were also drawn to show the direction of observational relationships between androgenic and metabolic parameters, which were adjusted according to the within-study variance show by circles. We also performed a subgroup analysis based on the hormonal assay methods. For all results, p-values $<0.05$ were considered significant. Statistical analysis was done using STATA software (version 10; STATA, INC., college station, TX, USA).

\section{Results}

\section{Search results and study selection and study characteristics}

-Fig. 1 illustrates the literature search and its results. Among the 33 studies (with 55 study groups) selected, 13 were RCTs [23-35], 6 NRS [36-41], 6 cross-sectionals [5, 13, 42-45], 3 case-controls [46-48], and 5 cohorts [3,49-52]. The study population consisted of 9905 PCOS patients with a mean age of 25.16 (range: $20.9-$ 31.00 ) years and a mean BMI of 27.61 (range: $20.90-36.40$ ) kg/m². Main characteristics of the studies included are listed in > Table 1.

\section{Results of meta-regression analyses}

Results of univariate weighted linear meta-regression analyses did not show any significant relationships between of androgens and some metabolic parameters including FBS and HOMA-IR. However, we found significant relationships between androgenic markers, and insulin and lipid profiles.

Total testosterone was not significantly related to metabolic parameters; after adjustment for age and $\mathrm{BMI}$, it was significantly associated with LDL-C ( $\beta=0.006 ; 95 \% \mathrm{Cl}: 0.002,0.01)$, HDL-C $(\beta=-0.009 ; 95 \% \mathrm{Cl}:-0.02,-0.001)$ and SBP $(\beta=-0.01 ; 95 \% \mathrm{Cl}$ : $-0.03,-0.00)$. Other relationships between tT and metabolic parameters were not significant ( $>$ Table 2 and $\triangleright$ Fig. 2 ).

The association between $\mathrm{fT}$ and fasting insulin was significant ( $\beta=0.49 ; 95 \% \mathrm{Cl}: 0.05,0.91)$; it was also associated with fasting insulin after adjustment for confounders. In addition, we found a reverse significant relationship between $\mathrm{fT}$ and $\mathrm{HDL}-\mathrm{C}(\beta=-0.41 ; 95 \%$ $\mathrm{Cl}:-0.70,-0.12)$; this relationship remained after adjustment for confounders. Other associations between $\mathrm{fT}$ and metabolic parameters were not significant ( $\triangleright$ Table $\mathbf{2}$ and $\triangleright$ Fig. 2 ).

We found a significant association between A4 and TG after adjustment for PCOS diagnostic criteria ( $\beta=0.02 ; 95 \% \mathrm{Cl}: 0.00,0.04)$. We also observed a significant association between A4 and TC ( $\beta=-0.05 ; 95 \% \mathrm{Cl}:-0.08,-0.007)$; this relationship remained after adjustment for quality assessment, ethnicity and hormonal assay methods. A reverse significant association was observed between A4 and HDL-C after adjustment for PCOS diagnostic criteria, and hormonal assay methods. Other relationships between A4 and metabolic parameters were non-significant ( $>$ Table 2 and $\triangleright$ Fig. 3 ).

There was a significant association between DHEAS and TC after adjustment for age and $\mathrm{BMI}(\beta=0.03 ; 95 \% \mathrm{Cl}$ : 0.006, 0.05). We observed a significant association between DHEAS and LDL-C ( $\beta=0.02 ; 95 \% \mathrm{Cl}: 0.001,0.03)$; this relationship remained after adjustment for confounders. There was also a significant negative relationship between DHEAS and HDL-C $(\beta=-0.03 ; 95 \% \mathrm{Cl}:-0.06$, 


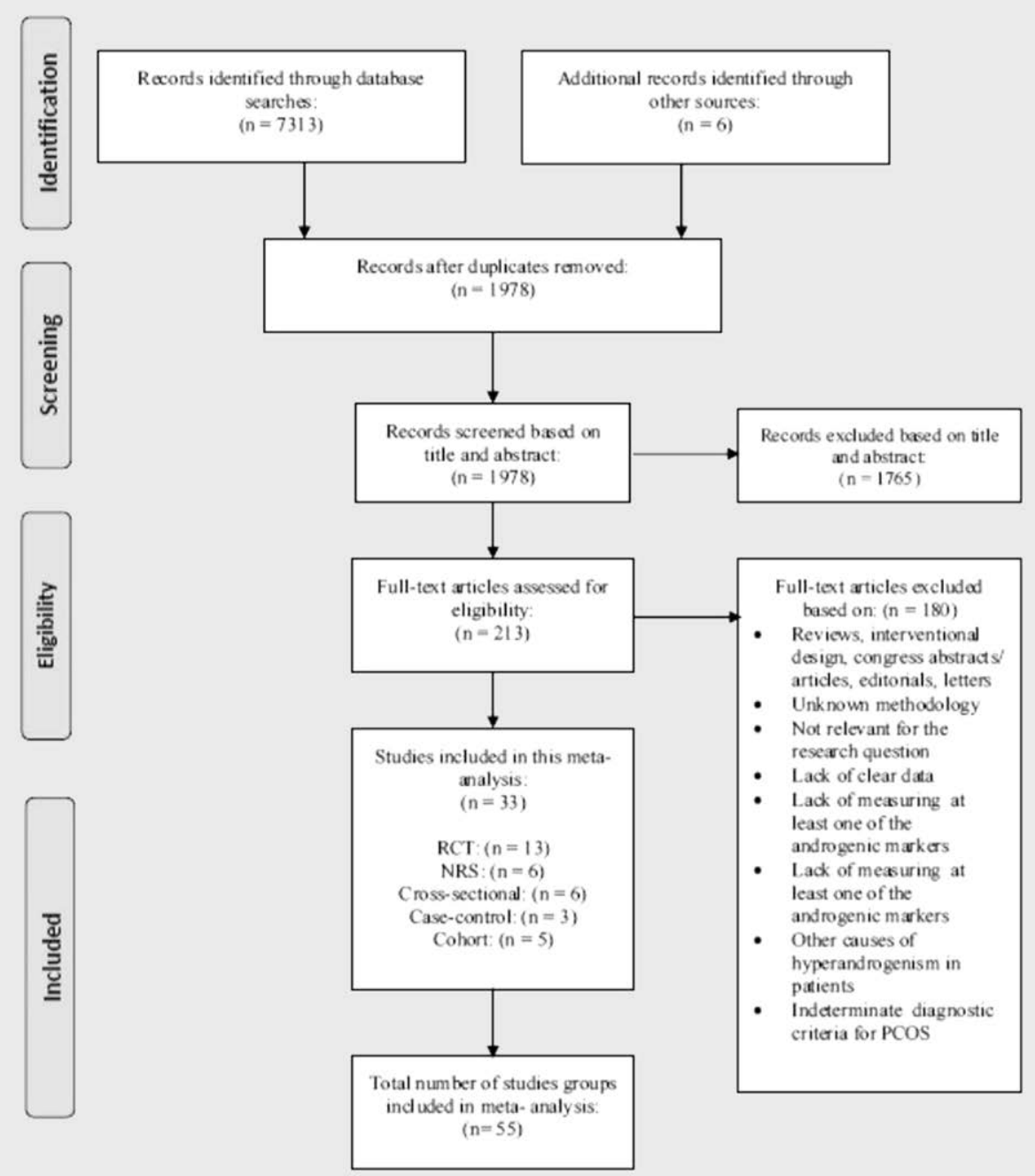

- Fig. 1 Flow diagram of study selection.

-0.001); this relationship remained after adjustment for study design, ethnicity and hormonal assay method ( $\vee$ Table 2 and $\triangleright$ Fig. 3).

No significant association was found between blood pressure and androgenic markers except tT after adjustment for age and BMI $(\beta=-0.01 ; 95 \% \mathrm{Cl}:-0.03,-0.00)$. We found significant heterogeneities for androgenic and metabolic parameters (supplementary files 1 and 2 ).

\section{Results of subgroup analysis}

Results of subgroup analysis based on the hormonal assay methods showed that when measurements were done by Radioimmunoassay, or chemi-/elecrtrochemiluminescence, some associations between androgenic and metabolic parameters (in particular fasting insulin, TC and HDL-C) were significant, confirming our previous results. See detailed results in the supplementary file 3.

\section{Publication bias}

Egger's test did not show any significant statistical publication bias among studies included for parameters measured; therefore, trim and fill correction were not applied (Supplementary file 1).

\section{Risk of bias assessment}

Supplementary file $\mathbf{4}$ shows details of risk of bias of published studies. Most RCT studies were at low risk of bias of random sequence generation, incomplete outcome data and selective outcome reporting; in these studies, some biases were more probable like blinding of allocation concealment, blinding of participant and personnel and outcome assessment.

Most NRS were at low risk of bias of confounding, selection of participants, interventions classification, and selection of the reported results. While most cross-sectional and case control studies were not at high risk of bias of assessment of exposure, development of outcome of interest in case and controls and selection of cases, some studies included had high risk of bias in selection of controls and adjustment for prognostic variables.

Although cohort studies were at low risk of bias of selection, assessment of exposure, present of outcome of interest at start of study, outcome assessment and adequacy of duration follow-ups, some studies included had serious risk biases in control of prognostic variables. 


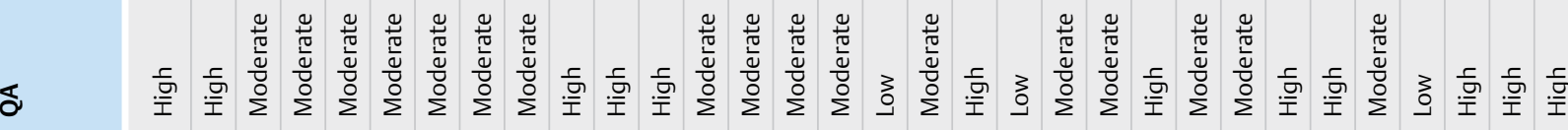

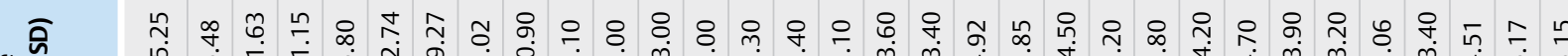

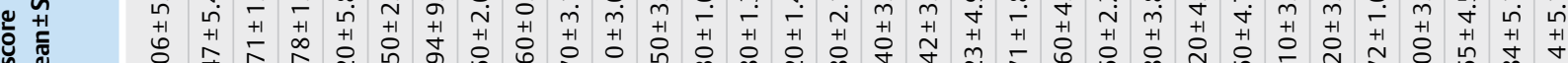

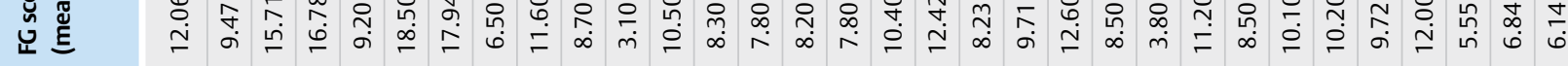

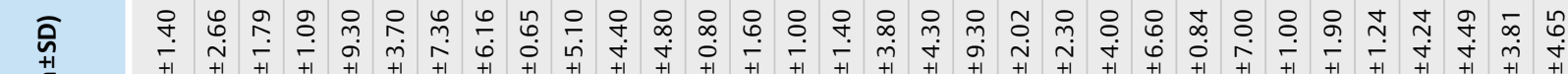

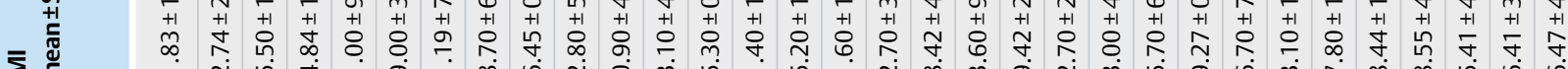

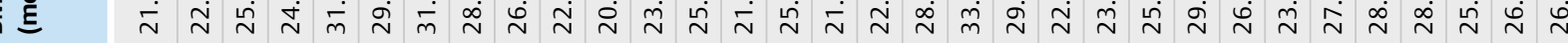

⿹ $\quad$ ํ.

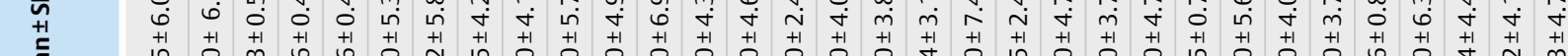

g

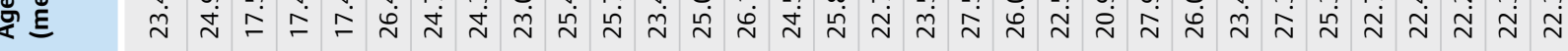

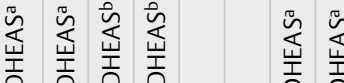

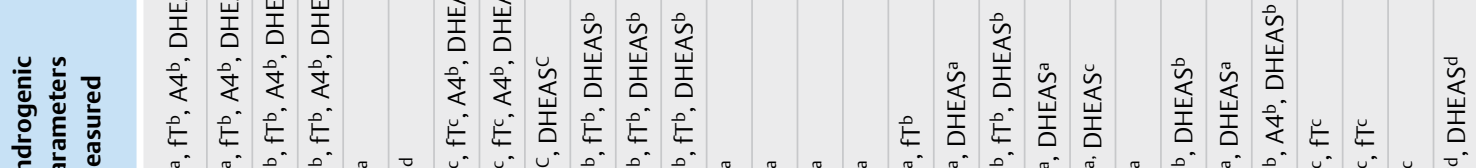

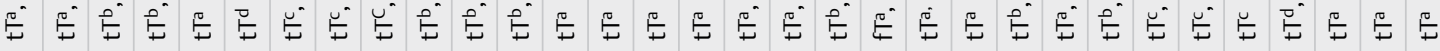

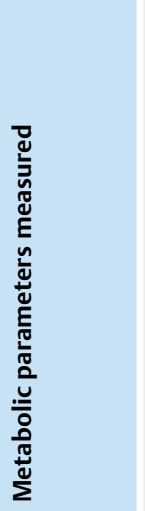

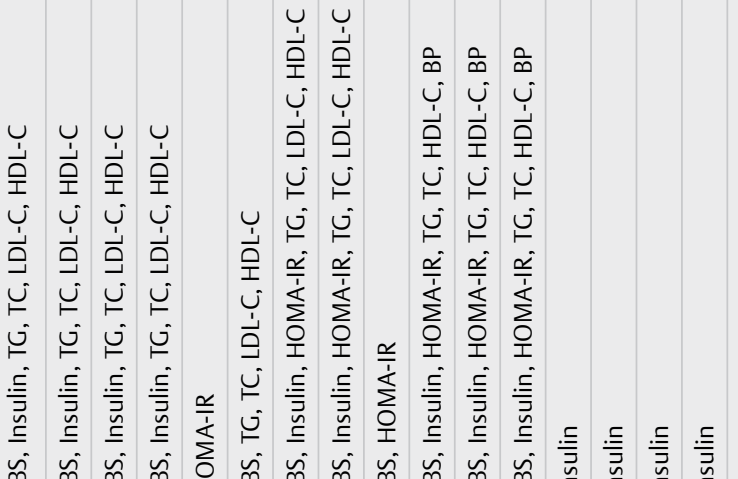

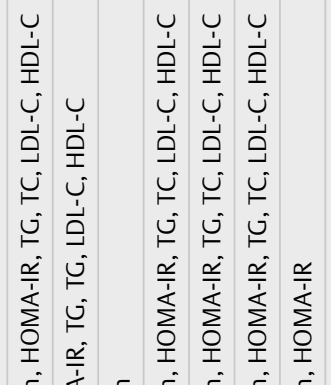

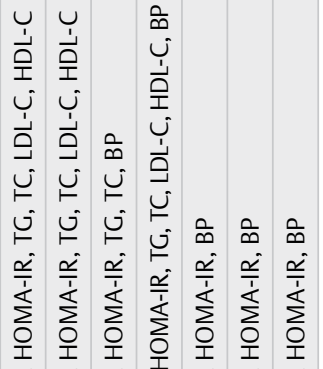

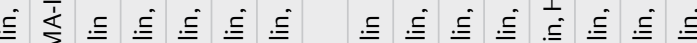

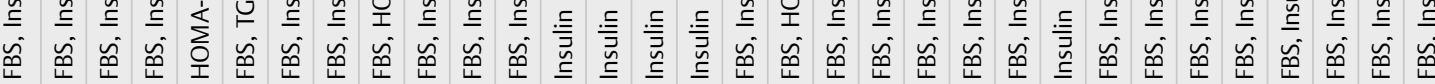

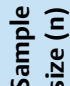

ㅇำ

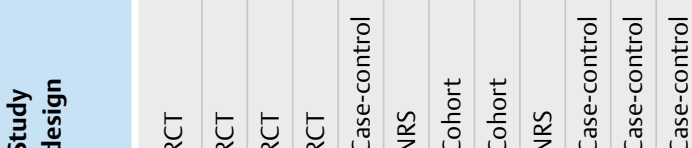

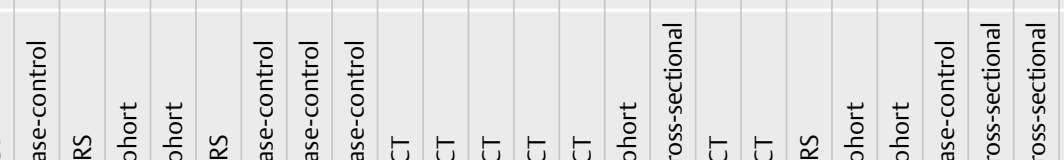

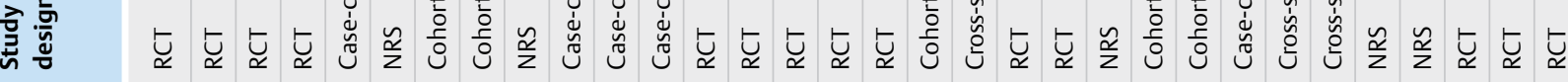

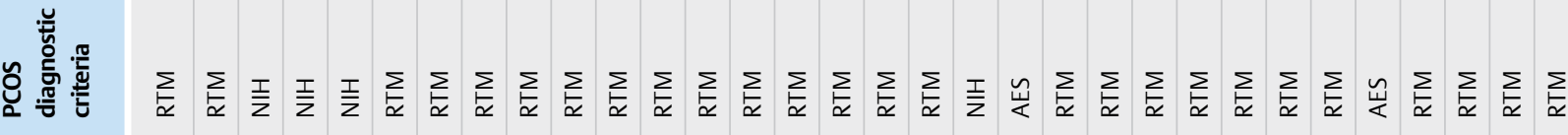

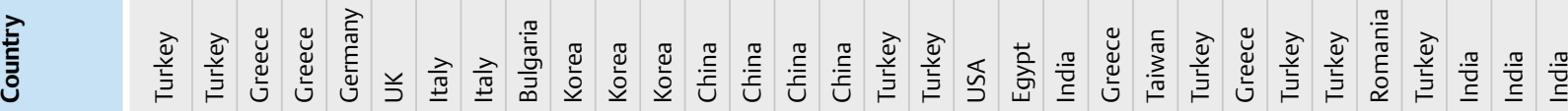

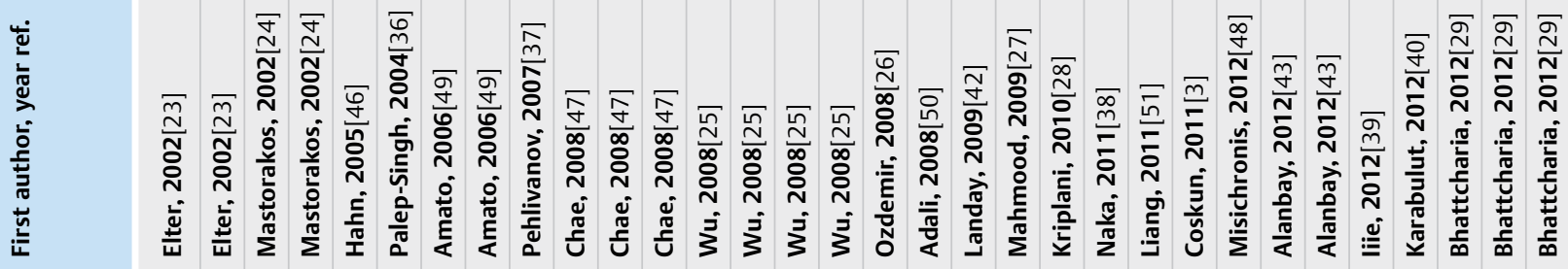




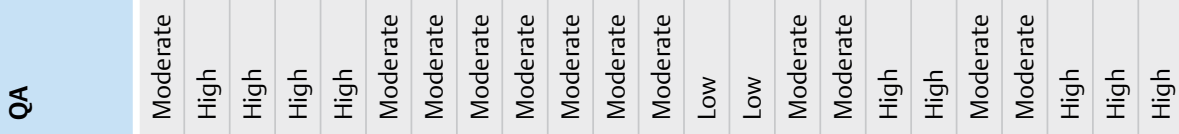

ิิ)

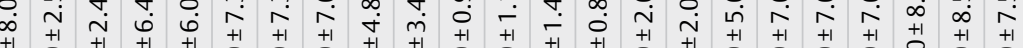

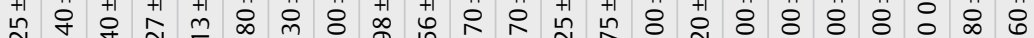

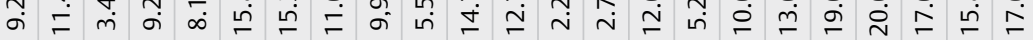

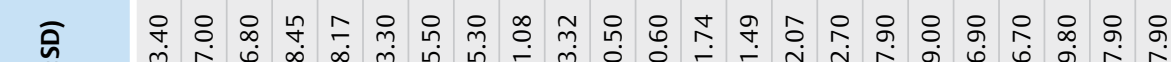

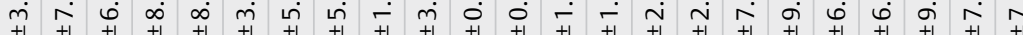

- 元 $\quad \begin{gathered}0 \\ 0\end{gathered}$

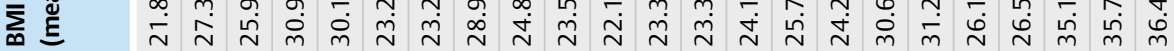

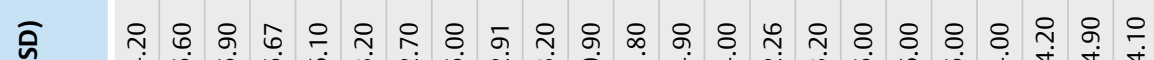

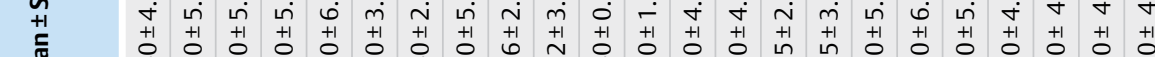
$q$
$q$

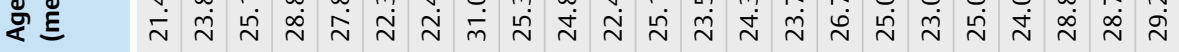

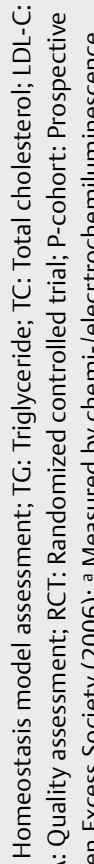

参厸

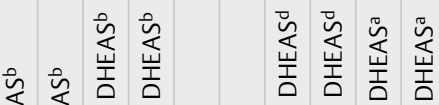

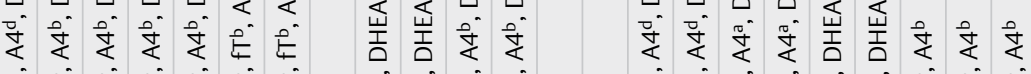

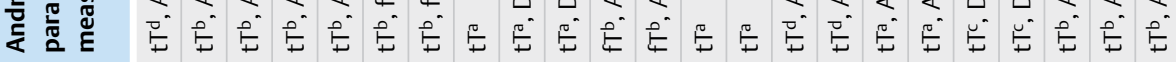
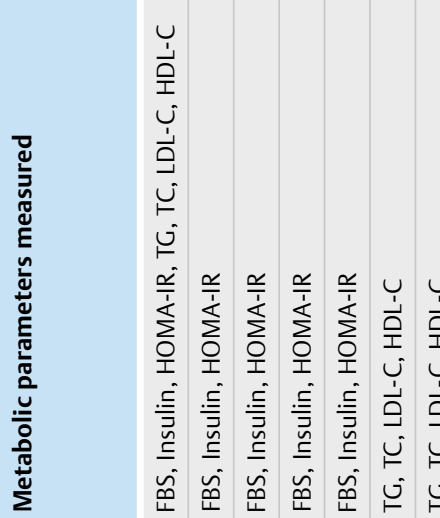

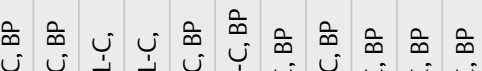

兰芯芯

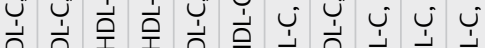
产

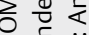

演峞崖

言

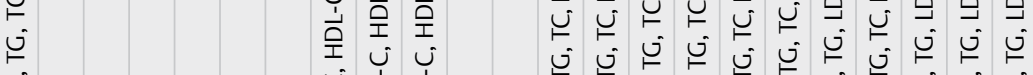

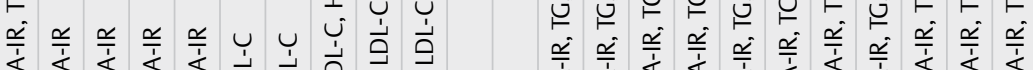

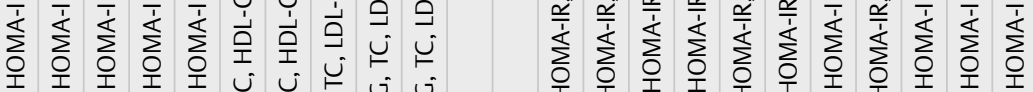
I I I T I ư

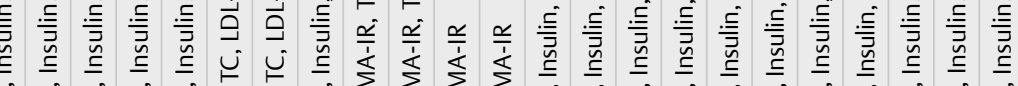

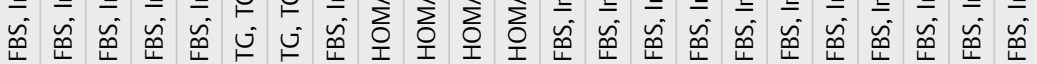

产竞

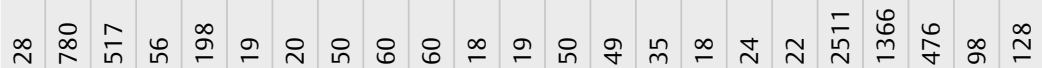

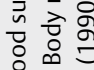

응

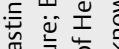

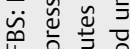

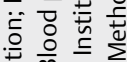

. $\frac{0}{\infty} \frac{1}{\pi} \sum_{0}$

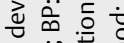

는

范

苟

טิ

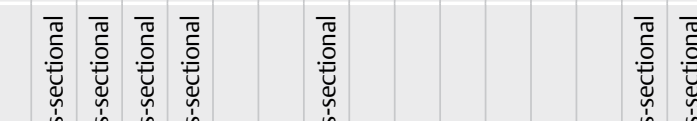

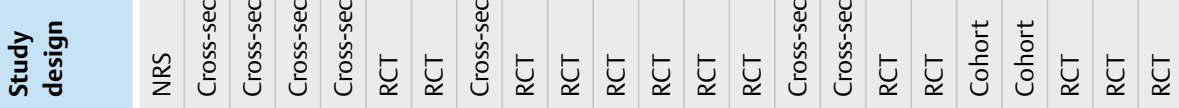

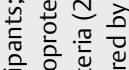

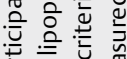

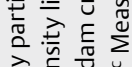

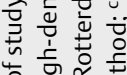

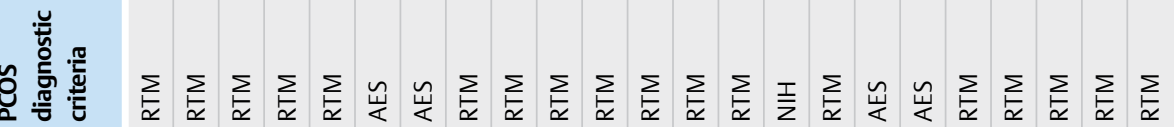

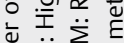

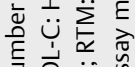

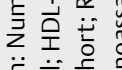

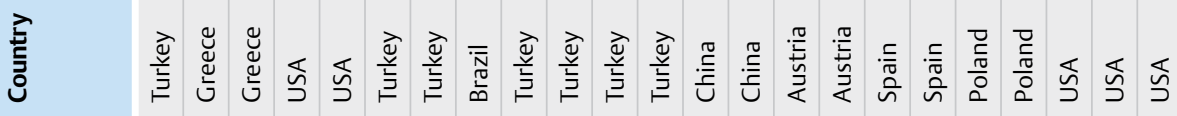

핳 㟧 总

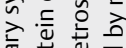


- Table 2 Meta-regression results for univariate and multiple (adjusted effect) models to assess the observational relationships between androgenic and metabolic parameters.

\begin{tabular}{|c|c|c|c|c|c|}
\hline \multirow{2}{*}{$\begin{array}{l}\text { Para- } \\
\text { meter }\end{array}$} & \multirow[t]{2}{*}{ Models } & tT & fT & A4 & DHEAS \\
\hline & & $\beta(95 \% \mathrm{Cl}$ for $\beta)$ & $\beta(95 \% \mathrm{Cl}$ for $\beta)$ & $\beta(95 \% \mathrm{Cl}$ for $\beta)$ & $\beta(95 \% \mathrm{Cl}$ for $\beta)$ \\
\hline \multirow[t]{7}{*}{ FBS } & unadjusted model & $0.00(-0.01,0.02)$ & $0.25(-0.43,0.92)$ & $-0.04(-0.12,0.03)$ & $0.004(-0.02,0.03)$ \\
\hline & adjusted for age and BMI & $0.01(-0.006,0.02)$ & $0.13(-0.67,0.94)$ & $-0.04(-0.11,0.03)$ & $0.009(-0.02,0.05)$ \\
\hline & adjusted for PCOS diagnosis criteria & $0.00(-0.007,0.02)$ & $0.22(-0.48,0.93)$ & $-0.02(-0.09,0.05)$ & $0.006(-0.02,0.04)$ \\
\hline & adjusted for quality assessment & $0.00(-0.008,0.01)$ & $0.24(-0.47,0.95)$ & $-0.06(-0.14,0.01)$ & $0.008(-0.02,0.04)$ \\
\hline & adjusted for study design & $0.00(-0.009,0.02)$ & $0.19(-0.48,0.86)$ & $-0.02(-0.08,0.03)$ & $0.006(-0.02,0.04)$ \\
\hline & adjusted for ethnic & $0.01(-0.007,0.02)$ & $0.26(-0.53,1.0)$ & $-0.06(-0.15,0.03)$ & $0.01(-0.02,0.04)$ \\
\hline & adjusted for hormonal assay methods & $0.00(-0.009,0.02)$ & $0.28(-0.62,1.1)$ & $0.04(-0.12,0.04)$ & $0.005(-0.03,0.03)$ \\
\hline \multirow{7}{*}{$\begin{array}{l}\text { Fasting } \\
\text { insulin }\end{array}$} & unadjusted model & $0.007(-0.006,0.022)$ & $0.49(0.05,0.91)^{*}$ & $0.02(-0.07,0.10)$ & $-0.001(-0.04,0.03)$ \\
\hline & adjusted for age and BMI & $0.01(-0.003,0.03)$ & $0.51(0.003,1.01)^{*}$ & $0.02(-0.08,0.12)$ & $-0.007(-0.04,0.03)$ \\
\hline & adjusted for PCOS diagnosis criteria & $0.008(-0.005,0.02)$ & $0.48(-0.006,0.96)$ & $0.05(-0.03,0.14)$ & $-0.005(-0.04,0.03)$ \\
\hline & adjusted for quality assessment & $0.01(-0.001,0.03)$ & $0.48(0.02,0.94)^{*}$ & $0.009(-0.10,0.12)$ & $0.001(-0.03,0.03)$ \\
\hline & adjusted for study design & $0.005(-0.01,0.02)$ & $0.45(0.02,0.87)^{*}$ & $-0.05(-0.12,0.02)$ & $0.006(-0.04,0.03)$ \\
\hline & adjusted for ethnic & $0.004(-0.01,0.02)$ & $0.50(0.05,0.95)^{*}$ & $0.02(-0.09,0.13)$ & $-0.004(-0.04,0.03)$ \\
\hline & adjusted for hormonal assay methods & $0.02(-0.02,0.06)$ & $0.50(0.02,0.95)^{*}$ & $0.03(-0.06,0.12)$ & $-0.008(-0.05,0.03)$ \\
\hline \multirow{7}{*}{$\begin{array}{l}\text { HOMA- } \\
\text { IR }\end{array}$} & unadjusted model & $0.004(-0.07,0.08)$ & $0.38(-1.90,2.70)$ & $-0.002(-0.33,0.32)$ & $-0.08(-0.28,0.10)$ \\
\hline & adjusted for age and BMI & $0.00(-0.09,0.08)$ & $-0.93(-3.71,1.80)$ & $-0.27(-0.77,0.21)$ & $-0.08(-0.30,0.13)$ \\
\hline & adjusted for PCOS diagnosis criteria & $0.01(-0.06,0.08)$ & $-0.67(-2.76,1.40)$ & $0.12(-0.21,0.46)$ & $-0.07(-0.27,0.12)$ \\
\hline & adjusted for quality assessment & $0.008(-0.06,0.08)$ & $0.16(-2.35,2.60)$ & $-0.11(-0.49,0.26)$ & $-0.08(-0.27,0.11)$ \\
\hline & adjusted for study design & $0.009(-0.07,0.08)$ & $0.65(-1.99,3.29)$ & $0.02(-0.26,0.29)$ & $-0.09(-0.29,0.11)$ \\
\hline & adjusted for ethnic & $-0.04(-0.10,0.04)$ & $0.20(-2.31,2.70)$ & $-0.006(-0.47,0.45)$ & $-0.09(-0.28,0.10)$ \\
\hline & adjusted for hormonal assay methods & $0.02(-0.26,0.31)$ & $0.40(-2.17,2.90)$ & $0.02(-0.33,0.36)$ & $-0.09(-0.30,0.11)$ \\
\hline \multirow[t]{7}{*}{ TG } & unadjusted model & $0.006(-0.002,0.003)$ & $0.04(-0.03,0.11)$ & $0.01(-0.01, .04)$ & $0.003(-0.003,0.01)$ \\
\hline & adjusted for age and BMI & $0.006(-0.001,0.002)$ & $0.05(-0.03,0.12)$ & $0.01(-0.02,0.05)$ & $0.002(-0.004,0.009)$ \\
\hline & adjusted for PCOS diagnosis criteria & $0.00(-0.002,0.003)$ & $0.04(-0.03,0.12)$ & $0.02(0.00,0.04) *$ & $0.003(-0.002,0.01)$ \\
\hline & adjusted for quality assessment & $0.00(-0.002,0.00)$ & $0.05(-0.03,0.12)$ & $0.009(-0.03,0.04)$ & $0.003(-0.004,0.01)$ \\
\hline & adjusted for study design & $0.00(-0.002,0.003)$ & $0.04(-0.04,0.11)$ & $-0.003(-0.03,0.02)$ & $0.003(-0.003,0.01)$ \\
\hline & adjusted for ethnic & $0.00(-0.002,0.002)$ & $0.04(-0.04,0.12)$ & $0.02(-0.02,0.04)$ & $0.006(-0.001,0.01)$ \\
\hline & adjusted for hormonal assay methods & $0.001(-0.005,0.006)$ & $0.04(-0.04,0.12)$ & $0.02(-0.01,0.04)$ & $0.004(-0.00,0.01)$ \\
\hline \multirow[t]{7}{*}{ TC } & unadjusted model & $0.002(-0.004,0.007)$ & $0.09(-0.09,0.26)$ & $-0.05(-0.08,-0.007)^{*}$ & $0.01(-0.005,0.03)$ \\
\hline & adjusted for age and BMI & $0.004(-0.0003,0.008)$ & $0.07(-0.13,0.27)$ & $-0.04(-0.11,0.01)$ & $0.03(0.006,0.05)^{*}$ \\
\hline & adjusted for PCOS diagnosis criteria & $0.002(-0.004,0.006)$ & $0.08(-0.10,0.27)$ & $-0.02(-0.05,0.00)$ & $0.02(-0.001,0.04)$ \\
\hline & adjusted for quality assessment & $0.00(-0.004,0.006)$ & $0.10(-0.09,0.28)$ & $-0.06(-0.09,-0.01)^{*}$ & $0.01(-0.006,0.03)$ \\
\hline & adjusted for study design & $0.003(-0.002,0.008)$ & $0.07(-0.10,0.25)$ & $-0.04(-0.07,-0.005)$ & $0.01(-0.006,0.03)$ \\
\hline & adjusted for ethnic & $-0.001(-0.006,0.003)$ & $0.08(-0.11,0.27)$ & $-0.05(-0.09,-0.00)^{*}$ & $0.01(-0.004,0.03)$ \\
\hline & adjusted for hormonal assay methods & $-0.02(-0.03,0.002)$ & $0.09(-0.10,0.27)$ & $-0.05(-0.09,-0.00)^{*}$ & $0.01(-0.00,0.03)$ \\
\hline \multirow[t]{7}{*}{ LDL-C } & unadjusted model & $0.001(-0.005, .006)$ & $0.16(-0.03,0.34)$ & $-0.006(-0.04,0.03)$ & $0.02(0.001,0.03)^{*}$ \\
\hline & adjusted for age and BMI & $0.006(0.002,0.01)^{*}$ & $0.13(-0.06,0.33)$ & $-0.02(-0.08,0.04)$ & $0.02(0.005,0.04)^{*}$ \\
\hline & adjusted for PCOS diagnosis criteria & $0.00(-0.004,0.007)$ & $0.14(-0.05,0.35)$ & $0.01(-0.03,0.04)$ & $0.02(0.001,0.03)^{*}$ \\
\hline & adjusted for quality assessment & $0.00(-0.004,0.01)$ & $0.17(-0.006,0.35)$ & $-0.04(-0.09,0.007)$ & $0.02(0.000,0.03)^{*}$ \\
\hline & adjusted for study design & $0.00(-0.004,0.01)$ & $0.16(-0.05,0.35)$ & $-0.02(-0.05,0.01)$ & $0.02(0.00,0.03)^{*}$ \\
\hline & adjusted for ethnic & $-0.001(-0.008,0.004)$ & $0.14(-0.05,0.30)$ & $-0.008(-0.05,0.03)$ & $0.02(0.001,0.03)^{*}$ \\
\hline & adjusted for hormonal assay methods & $-0.009(-0.03,0.01)$ & $0.15(-0.05,0.35)$ & $-0.004(-0.05,0.04)$ & $0.02(0.003, .03)^{*}$ \\
\hline \multirow{3}{*}{$\begin{array}{l}\mathrm{HDL}-\mathrm{C} \\
\text { SBP }\end{array}$} & unadjusted model & $-0.006(-0.02,0.003)$ & $-0.41(-0.70,-0.12)^{*}$ & $-0.05(-0.10,0.002)$ & $-0.03(-0.06,-0.001)^{*}$ \\
\hline & adjusted for age and BMI & $-0.009(-0.02,-0.001)^{*}$ & $-0.45(-0.76,-0.14)^{*}$ & $-0.07(-0.15,0.00)$ & $-0.02(-0.06,0.01)$ \\
\hline & adjusted for PCOS diagnosis criteria & $-0.001(-0.02,0.002)$ & $-0.44(-0.74,-0.13)^{*}$ & $-0.06(-0.10,-0.02)^{*}$ & $-0.03(-0.06,0.005)$ \\
\hline
\end{tabular}


> Table 2 Continued.

\begin{tabular}{|c|c|c|c|c|c|}
\hline \multirow{2}{*}{$\begin{array}{l}\text { Para- } \\
\text { meter }\end{array}$} & \multirow[t]{2}{*}{ Models } & tT & fT & A4 & DHEAS \\
\hline & & $\beta(95 \% \mathrm{Cl}$ for $\beta)$ & $\beta(95 \% \mathrm{Cl}$ for $\beta)$ & $\beta(95 \% \mathrm{Cl}$ for $\beta)$ & $\beta(95 \% \mathrm{Cl}$ for $\beta)$ \\
\hline & adjusted for quality assessment & $-0.007(-0.016,0.001)$ & $-0.45(-0.75,-0.15)^{*}$ & $-0.06(-0.13,0.02)$ & $-0.03(-0.06,0.00)$ \\
\hline & adjusted for study design & $-0.002(-0.01, .007)$ & $-0.38(-0.73,-0.05)^{*}$ & $-0.02(-0.08,0.03)$ & $-0.04(-0.08,-0.009)^{*}$ \\
\hline & adjusted for ethnic & $-0.002(-0.01,0.006)$ & $-0.40(-0.71,-0.10)^{*}$ & $-0.05(-0.11,0.007)$ & $-0.04(-0.07,-0.00)^{*}$ \\
\hline & adjusted for hormonal assay methods & $-0.03(-0.06,0.0007)$ & $-0.40(-0.74,-0.10)^{*}$ & $-0.06(-0.11,-0.00)^{*}$ & $-0.04(-0.07,-0.00)^{*}$ \\
\hline & unadjusted model & $-0.006(-.02, .009)$ & $0.18(-0.29,0.66)$ & $0.08(-0.12,0.27)$ & $0.12(-0.02,0.26)$ \\
\hline & adjusted for age and BMI & $-0.01(-0.03,-0.00)^{*}$ & - & $0.20(-1.09,1.50)$ & $0.22(-0.18,0.62)$ \\
\hline & adjusted for PCOS diagnosis criteria & $0.00(-0.02,0.015)$ & - & $0.09(-0.37,0.55)$ & $0.14(-0.03,0.31)$ \\
\hline & adjusted for quality assessment & $-0.003(-0.02,0.01)$ & - & - & $0.11(-0.05,0.30)$ \\
\hline & adjusted for study design & $-0.01(-0.04,0.01)$ & - & $0.08(-0.12,0.27)$ & $0.14(-0.03,0.31)$ \\
\hline & adjusted for ethnic & $-0.004(-0.02,0.008)$ & - & - & $0.03(-0.14,0.20)$ \\
\hline & adjusted for hormonal assay methods & - & - & $0.09(-0.37,0.55)$ & $0.12(-0.04,0.28)$ \\
\hline \multirow[t]{7}{*}{ DBP } & unadjusted model & $-0.002(-0.03,0.02)$ & $0.42(-1.50,2.30)$ & $0.09(-0.11,0.30)$ & $0.02(-0.15,0.19)$ \\
\hline & adjusted for age and BMI & $-0.02(-0.04,0.005)$ & - & $0.20(-0.90,1.40)$ & $-0.07(-0.34,0.19)$ \\
\hline & adjusted for PCOS diagnosis criteria & $0.005(-0.02,0.03)$ & - & $0.10(-0.30,0.55)$ & $0.02(-0.18,0.21)$ \\
\hline & adjusted for quality assessment & $-0.002(-0.02,0.02)$ & - & - & $-0.03(-0.28,0.22)$ \\
\hline & adjusted for study design & $0.00(-0.03,0.033)$ & - & $0.09(-0.11,0.30)$ & $0.02(-0.18,0.20)$ \\
\hline & adjusted for ethnic & $0.002(-0.02,0.02)$ & - & - & $-0.02(-0.14,0.09)$ \\
\hline & adjusted for hormonal assay methods & - & - & $0.10(-0.35,0.55)$ & $0.01(-0.21,0.22)$ \\
\hline
\end{tabular}

\section{Discussion}

In this systematic review and meta-analysis, we assessed the possible relationships between androgenic markers of hyperandrogenism and metabolic findings in women with PCOS. Because it is well known that all these parameters may be affected by several factors such as age, BMI, ethnicity, and methods of hormonal of assay $[1,13,53-58]$; in performing the meta-analysis, we adjusted the results for all these important confounders.

The results for possible correlations between biochemical parameters of hyperandrogenism and metabolic findings were mixed, generally negative but with some significant correlation. In fact, some androgenic parameters but especially fT were significantly associated with insulin levels, HDL-C, and LDL-C. Interestingly, the significant association between $\mathrm{fT}$ and fasting insulin remained after adjustment for confounders including as age, BMI, quality assessment, study design, ethnicity and methods of assay. A significant reverse association between $\mathrm{fT}$ and $\mathrm{HDL}-\mathrm{C}$ was also detected; adjusting for most confounders confirmed this result.

Of course, a simple explanation of these results is that circulating values of free testosterone are highly depending on sex hormone binding globulin (SHBG) levels that are low in presence of high insulin levels. Because of it, some experts have expressed doubts on the value of the assessment of free testosterone levels as an indicator of increased androgen production [59].
Insulin resistance is one of the most common metabolic disorders in women with PCOS $[60,61]$, which is observed in a large number of PCOS patients with HA. It has been reported that high insulin levels exert a direct positive effect on androgen production in women with PCOS $[48,62]$. In addition, hyperinsulinemia increases the production of insulin growth factors I (IGF-I) and II in the liver [55], which lead to increase in androgen production [63]. IGF-I inhibits the aromatase enzyme that prevents the conversion of testosterone into estrogen. Insulin can also increase LH action in ovaries [64]. Moreover, hyperinsulinemia decreases liver production of SHBG, contributing to increased activity of free testosterone [65]. Also, insulin resistance reduces SHBG and raises free circulating testosterone [48, 62]. Insulin resistance is often associated with dyslipidemia as a common risk factor for CVD in patients with PCOS $[66,67]$. PCOS patients with $\mathrm{HA}$ also have an increased risk for metabolic syndrome (MetS) [68]. A progressive accumulation of fat, which is often associated with dyslipidemia and an increase in fasting insulin and insulin resistance has been observed in PCOS patients with HA [4]. In fact, HA, related to PCOS, can aggravate metabolic and reproductive disorders associated with PCOS including dyslipidemia and MS [69].

At the contrary, the findings of this meta-analysis showed that tT was not significantly associated with any metabolic parameters. After adjustment for age and BMI, tT showed a positive significant 
Bubble plot of Metabolic Factors aqainst tT
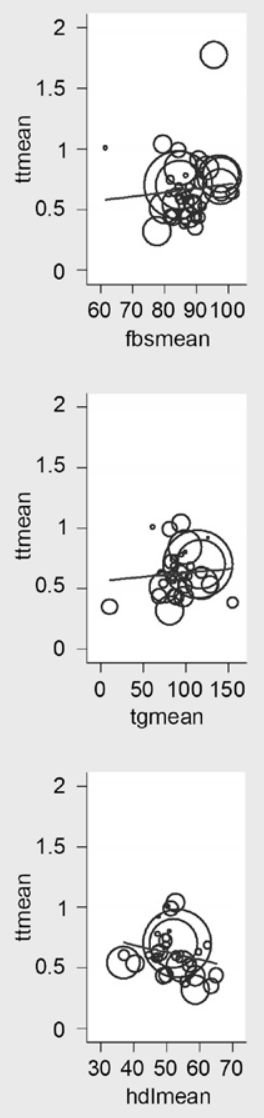
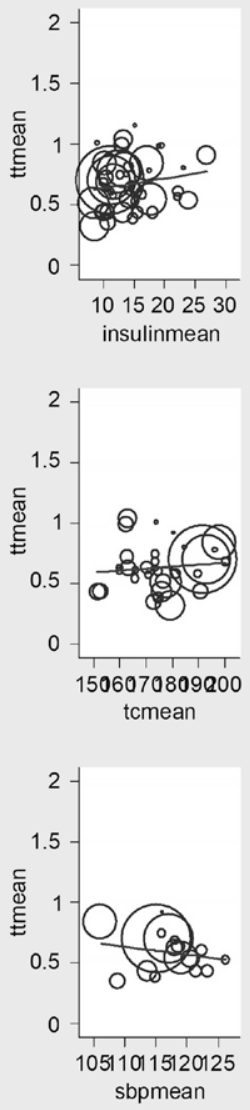
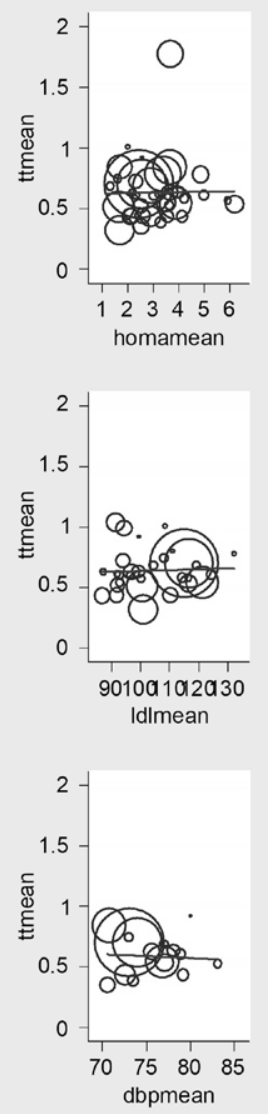

Bubble plot of Metabolic Factors against $\mathrm{fT}$
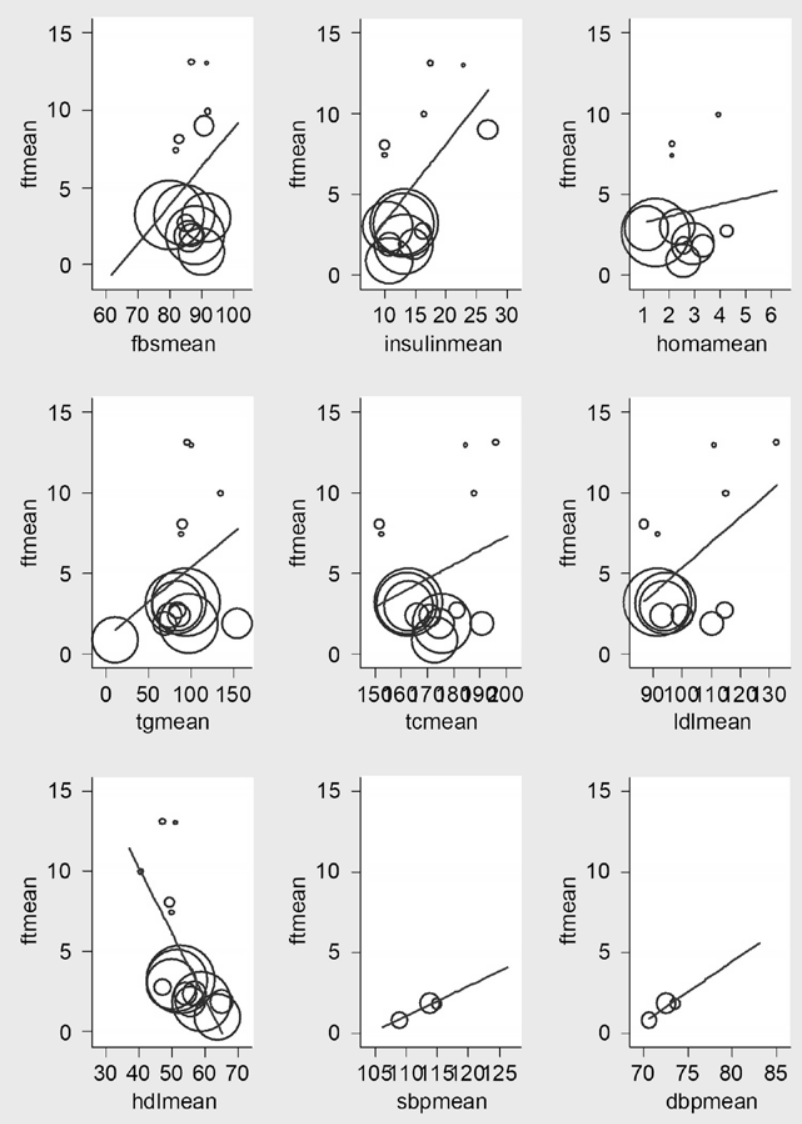

relationship with $L D L-C$ and a reverse significant relationship with HDL-C and SBP.

However, adjusting for other confounders including diagnosis criteria for PCOS, study design, ethnicity, and methods of hormonal assay did not associate with any change in the relationships of tT and metabolic parameters. Particularly interesting is the finding that no correlation between $\mathrm{tT}$ and metabolic parameters of PCOS was observed also when we evaluated different subgroups of studies divided according the assay method of total testosterone. While there were minor associations between $\mathrm{A} 4, \mathrm{TC}$, and HDL-C, in general we did not find significant associations between this androgenic marker and metabolic parameters.

Finally, our study showed that DHEAS had a positive significant association with LDL-C and reverse significant association with HDLC; after adjustment for the most important confounders such as age, BMI, and methods of assay, this associations remained. This finding is particularly provocative because it has been suggested that low DHAES levels may be related to a worst metabolic pattern [70].

We did not find significant associations between FBS and androgens. We also did not detect any association between HOMA-IR and androgenic parameters. Out study results showed a reverse significant association between androgens and HDL-C and a positive significant association between LDL-C and androgens, where- as we did not detect significant associations with other lipids such as TC and TG.

The limitations of this study should be considered in interpretation of the findings. Most studies in this meta-analysis recruited participants from different settings such as hospitals and clinics, which may represent a population with more severe manifestations of PCOS. In this study, we could not investigate the association between biochemical and metabolic parameters, considering all confounders simultaneously because of a limited number of included studies. Our findings can be also limited by variations in lifestyle factors in patients with PCOS that could have affected their metabolic profiles. We have used HOMA-IR as a surrogate marker for assessing of IR. In spite of the good correlation between HOMA-IR and gold standard clamp methods [71], this method might be inaccurate in PCOS subjects [72].

While we aimed to minimize all possible bias in this meta-analysis, it should be noted that there was a significant heterogeneity in androgenic and metabolic parameters among studies. These heterogeneities were partly predictable and may have resulted from clinical heterogeneity related to variability in age, BMI, PCOS diagnostic criteria, hormonal assay methods, race, and ethnicity. We used random effect analysis to deal with the problem. To reduce selection bias and heterogeneity, we excluded studies, that 
Bubble Plot of Metabolic Factors Against DHEAS
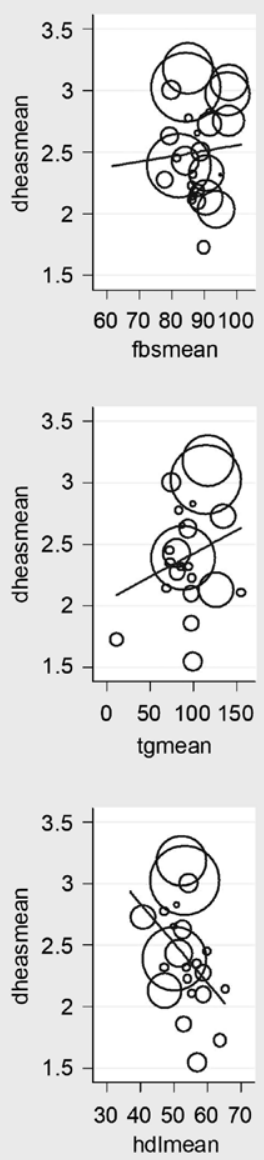
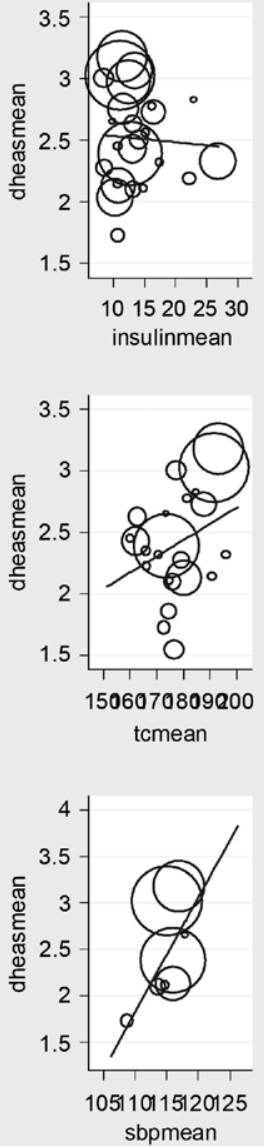
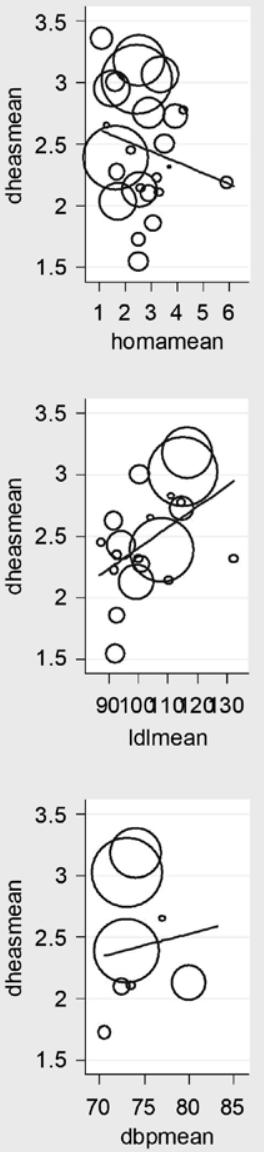

Bubble Plot of Metabolic Factors Against A4
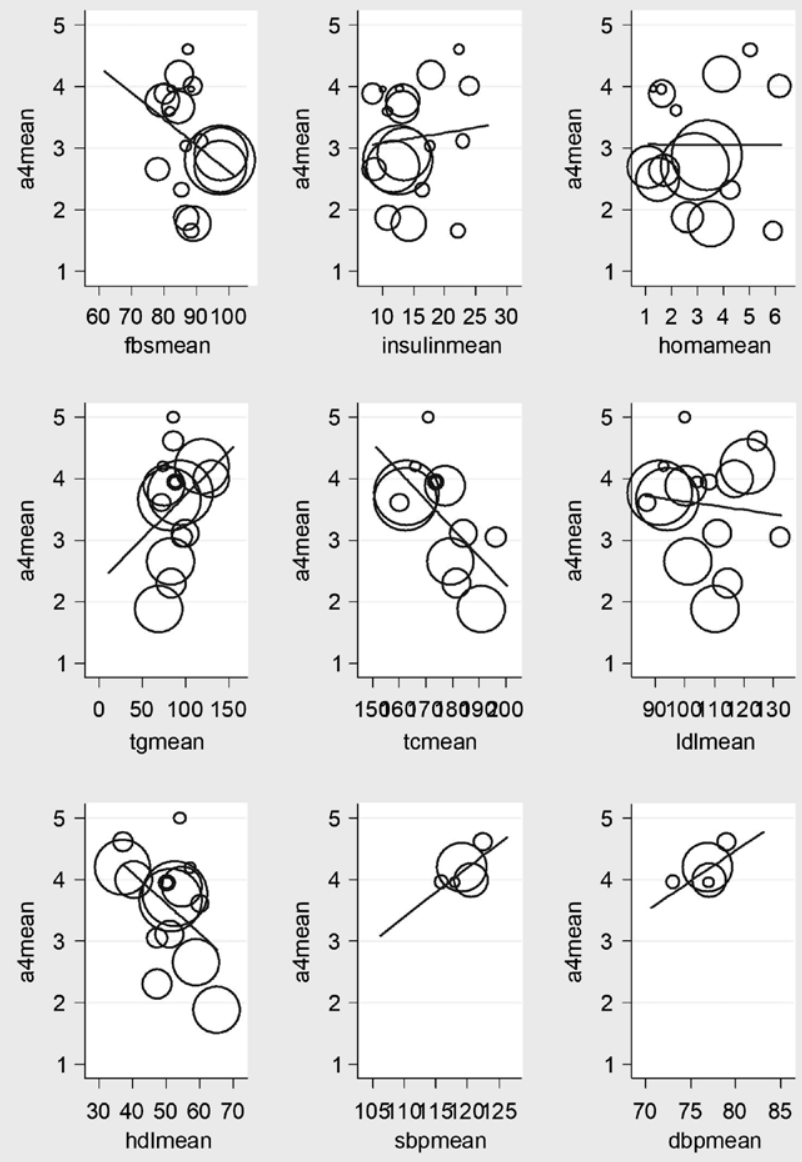

- Fig. 3 Bubble plot of the univariate relationships between A4, DHEAS, and metabolic parameters.

their study with populations including patients with chronic disease such as diabetes, cardiovascular, or thyroid disorders. It is important to consider that the majority of patients were young (mean age 25 years) without having obesity (mean BMI 27.61). So, caution should be applied in extrapolating these results for wider applications. Finally our meta-analysis could not include LC.MS methods for measuring androgens because no sufficient number of studies used this new methodology.

The present study provides some clues for better understanding of the pathophysiology of PCOS, which may be helpful in decision-making process and managing patients with this syndrome. Since no sufficient number of studies used LC.MS for measuring androgens, more researches are necessary to assess the androgens levels by this accurate method in patients with PCOS.

\section{Conclusion}

In conclusion, our meta-analysis shows few relationships between biochemical parameters of hyperandrogenism and metabolic findings in women with PCOS. Some correlation with serum lipids was observed but was similar to that found when analyzing the effect of androgens in general population (males and females). Only fT showed a correlation with insulin levels and insulin resistance but it may depend on the well-known effect of insulin on SHBG. Probably, insulin excess has limited effects on androgen ovarian production.

\section{Authors' Contributions}

MA was involved in study design, search in databases, study selection, data analysis, manuscript drafting, and submitting the manuscript. FRT was involved in study design, data analysis, manuscript drafting, and critical discussion. SBG contributed searching the databases and study selection. RBY contributed in study selection, data analysis, and critical discussion. FA contributed to study design, execution and manuscript drafting. EC was involved in data analysis, manuscript drafting, revising and critical discussion. All authors read and approved the final manuscript.

\section{Acknowledgment}

The authors wish to acknowledge Ms Niloofar Shiva for critical editing of English grammar and syntax of the manuscript. 


\section{Funding}

This meta-analysis was funded by the Research Institute for Endocrine Sciences of the Shahid Beheshti University of Medical Sciences.

\section{Conflict of Interest}

The authors declare that they have no conflict of interest.

\section{References}

[1] Baptiste CG, Battista M-C, Trottier A, Baillargeon J-P. Insulin and hyperandrogenism in women with polycystic ovary syndrome. J Steroid Biochem Mol Biol 2010; 122: 42-52

[2] Azziz R, Carmina E, Dewailly D, Diamanti-Kandarakis E, Escobar-Morreale HF, Futterweit W, Janssen OE, Legro RS, Norman RJ, Taylor AE, Witchel SF. The androgen excess and PCOS society criteria for the polycystic ovary syndrome: The complete task force report. Fertil Steril 2009; 91: 456-488

[3] Coskun A, Ercan O, Arikan DC, Özer A, Kilinc M, Kiran G, Kostu B. Modified ferriman-gallwey hirsutism score and androgen levels in turkish women. Eur J Obstet Gynecol Reprod Biol 2011; 154: 167-171

[4] Malavazos AE, Cereda E, Ermetici F, Caccialanza R, Briganti S, Rondanelli M, Morricone L. The "lipid accumulation product" is associated with 2-h postload glucose outcomes in overweight/obese subjects with nondiabetic fasting glucose. Int J Endocrinol 2015; 836941

[5] Sales MF, Sóter MO, Cândido AL, Reis FMd, Sousa MO, Fernandes AP, Ferreira CN, Gomes KB. Ferriman-Gallwey score correlates with obesity and insulin levels in polycystic ovary syndrome: An observational study. Rev Soc Bras Clín Méd 2015; 13: 107-110

[6] Cussons AJ, Stuckey BG, Watts GF. Cardiovascular disease in the polycystic ovary syndrome: New insights and perspectives. Atherosclerosis 2006; 185: 227-239

[7] Burghen GA, Givens JR, Kitabchi AE. Correlation of hyperandrogenism with hyperinsulinism in polycystic ovarian disease. J Clin Endocrinol Metab 1980; 50: 113-116

[8] Cupisti S, Kajaia N, Dittrich R, Duezenli H, Beckmann MW, Mueller A. Body mass index and ovarian function are associated with endocrine and metabolic abnormalities in women with hyperandrogenic syndrome. Eur J Endocrinol 2008; 158: 711-719

[9] Moretti C, Lanzolla G, Moretti M, Gnessi L, Carmina E. Androgens and hypertension in men and women: A Unifying View. Curr Hyperten Rep 2017; 19: 44

[10] Chen M-J, Yang W-S, Yang J-H, Chen C-L, Ho H-N, Yang Y-S. Relationship between androgen levels and blood pressure in young women with polycystic ovary syndrome. Hypertension 2007; 49: 1442-1447

[11] Goodman NF, Cobin RH, Futterweit W, Glueck JS, Legro RS, Carmina E. American association of clinical endocrinologists, American college of endocrinology, and androgen excess and PCOS society disease state clinical review: Guide to the best practices in the evaluation and treatment of polycystic ovary syndrome-part 1. Endocr Pract 2015; 21: $1291-1300$

[12] Moher D, Liberati A, Tetzlaff J, Altman DG. Preferred reporting items for systematic reviews and meta-analyses: The PRISMA statement. Ann Intern Med 2009; 151: 264-269

[13] Panidis D, Tziomalos K, Papadakis E, Chatzis P, Kandaraki EA, Tsourdi EA, Vosnakis C, Katsikis I. The clinical significance and primary determinants of hirsutism in patients with polycystic ovary syndrome. Eur J Endocrinol 2013; 168: 871-877
[14] Moher D, Hopewell S, Schulz KF, Montori V, Gøtzsche PC, Devereaux P, Elbourne D, Egger M, Altman DG. CONSORT 2010 explanation and elaboration: Updated guidelines for reporting parallel group randomised trials. J Clin Epidemiol 2010; 63: e1-e37

[15] Quigley J, Thompson J, Halfpenny N, Scott D. Critical appraisal of non-randomized controlled studies-a review of recommended and commonly used tools. J Eval Clin Pract 2018, doi:10.1111/jep.12889 [Epub ahead of print]

[16] Higgins ], Altman DG. Assessing risk of bias in included studies. Cochrane handbook for systematic reviews of interventions: Cochrane book series 2008; 187-241

[17] Sterne JA, Hernán MA, Reeves BC, Savović J, Berkman ND, Viswanathan M, Henry D, Altman DG, Ansari MT, Boutron I. ROBINS-I: A tool for assessing risk of bias in non-randomised studies of interventions. BM] 2016; 355: i4919

[18] Higgins JP, Thompson SG, Deeks JJ, Altman DG. Measuring inconsistency in meta-analyses. BMJ 2003; 327: 557-560

[19] Borenstein M, Hedges LV, Higgins J, Rothstein HR. Front matter: Wiley Online Library; 2009

[20] Egger M, Smith GD, Schneider M, Minder C. Bias in meta-analysis detected by a simple, graphical test. BMJ 1997; 315: 629-634

[21] Taylor S, TWeedie R. Trim and fill: A simple funnel plot based method of testing and adjusting for publication bias in meta-analyses. Fort Collins, CO: Colorado State University; 1998

[22] Duval S, Tweedie R. Trim and fill: A simple funnel-plot-based method of testing and adjusting for publication bias in meta-analysis. Biometrics 2000; 56: 455-463

[23] Elter K, Imir G, Durmusoglu F. Clinical, endocrine and metabolic effects of metformin added to ethinyl estradiol-cyproterone acetate in non-obese women with polycystic ovarian syndrome: A randomized controlled study. Human Reprod 2002; 17: 1729-1737

[24] Mastorakos G, Koliopoulos C, Creatsas G. Androgen and lipid profiles in adolescents with polycystic ovary syndrome who were treated with two forms of combined oral contraceptives. Fertil Steril 2002; 77: 919-927

[25] Wu J, Zhu Y, jiang Y, Cao Y. Effects of metformin and ethinyl estradiol-cyproterone acetate on clinical, endocrine and metabolic factors in women with polycystic ovary syndrome. Gynecol Endocrinol 2008; 24: 392-398

[26] Özdemir S, Görkemli H, Gezginç K, Özdemir M, Kiyici A. Clinical and metabolic effects of medroxyprogesterone acetate and ethinyl estradiol plus drospirenone in women with polycystic ovary syndrome. Int J Gynecol Obstet 2008; 103: 44-49

[27] Mahmood M, EL-Kattan EA, EL-Aal HA, EL Lithy A, Ghamry NK, Sheta M. Evaluation of the clinical and biochemical effects of medical therapy in women with polycystic ovary syndrome. Med J Cairo Univ 2009; 77: 59-67

[28] Kriplani A, Periyasamy A], Agarwal N, Kulshrestha V, Kumar A, Ammini AC. Effect of oral contraceptive containing ethinyl estradiol combined with drospirenone vs. desogestrel on clinical and biochemical parameters in patients with polycystic ovary syndrome. Contraception 2010; 82: 139-146

[29] Bhattacharya SM, Jha A. Comparative study of the therapeutic effects of oral contraceptive pills containing desogestrel, cyproterone acetate, and drospirenone in patients with polycystic ovary syndrome. Fertil Steril 2012; 98: 1053-1059

[30] Kahraman K, Şükür YE, Atabekoğlu CS, Ateş C, Taşkın S, Çetinkaya ŞE, Tolunay HE, Özmen B, Sönmezer M, Berker B. Comparison of two oral contraceptive forms containing cyproterone acetate and drospirenone in the treatment of patients with polycystic ovary syndrome: A randomized clinical trial. Arch Gynecol Obstet 2014; 290: 321-328 
[31] Yildizhan R, Gokce Al, Yildizhan B, Cim N. Comparison of the effects of chlormadinone acetate versus drospirenone containing oral contraceptives on metabolic and hormonal parameters in women with PCOS for a period of two-year follow-up. Gynecol Endocrinol 2015; 31: 396-400

[32] Diri H, Karaburgu S, Acmaz B, Unluhizarci K, Tanriverdi F, Karaca Z, Kelestimur F. Comparison of spironolactone and spironolactone plus metformin in the treatment of polycystic ovary syndrome. Gynecol Endocrinol 2016; 32: 42-45

[33] Wang Q-Y, Song Y, Huang W, Xiao L, Wang Q-S, Feng G-M. Comparison of drospirenone-with cyproterone acetate-containing oral contraceptives, combined with metformin and lifestyle modifications in women with polycystic ovary syndrome and metabolic disorders: A prospective randomized control trial. Chin Med J 2016; 129: 883

[34] Alpañés M, Álvarez-Blasco F, Fernández-Durán E, Luque-Ramírez M, Escobar-Morreale HF. Combined oral contraceptives plus spironolactone compared with metformin in women with polycystic ovary syndrome: A one-year randomized clinical trial. Eur J Endocrinol 2017; 177: 399-408

[35] Engmann L, Jin S, Sun F, Legro RS, Polotsky A], Hansen KR, Coutifaris C, Diamond MP, Eisenberg E, Zhang $\mathrm{H}$. Racial and ethnic differences in the polycystic ovary syndrome metabolic phenotype. Am J Obstet Gynecol 2017; 216: e1-e13

[36] Palep-Singh M, Mook K, Barth J, Balen A. An observational study of Yasmin $^{\circledR}$ in the management of women with polycystic ovary syndrome. BMJ Sex Reprod Health 2004; 30: 163-165

[37] Pehlivanov B, Mitkov M. Efficacy of an oral contraceptive containing drospirenone in the treatment of women with polycystic ovary syndrome. Eur J Contracep Reprod Health Care 2007; 12: 30-35

[38] Naka KK, Kalantaridou SN, Bechlioulis A, Kravariti M, Kazakos N, Katsouras CS, Tsatsoulis A, Michalis LK. Effect of ethinylestradiol/ cyproterone acetate on endothelial function in young non-obese women with polycystic ovary syndrome: A pilot study. Gynecol Endocrinol 2011; 27: 615-621

[39] Ilie IR, Marian I, Mocan T, Ilie R, Mocan L, Duncea I, Pepene CE. Ethinylestradiol $30 \mu \mathrm{g}$-drospirenone and metformin: Could this combination improve endothelial dysfunction in polycystic ovary syndrome? BMC Endocr Disord 2012; 12: 1

[40] Karabulut A, Demirlenk S, Şevket O. Effects of ethinyl estradiol-cyproterone acetate treatment on metabolic syndrome, fat distribution and carotid intima media thickness in polycystic ovary syndrome. Gynecol Endocrinol 2012; 28: 245-248

[41] Aydin K, Cinar N, Aksoy DY, Bozdag G, Yildiz BO. Body composition in lean women with polycystic ovary syndrome: Effect of ethinyl estradiol and drospirenone combination. Contraception 2013; 87: 358-362

[42] Landay M, Huang A, Azziz R. Degree of hyperinsulinemia, independent of androgen levels, is an important determinant of the severity of hirsutism in PCOS. Fertil Steril 2009; 92: 643-647

[43] Alanbay I, Ercan CM, Sakinci M, Coksuer H, Ozturk M, Tapan S. A macrophage activation marker chitotriosidase in women with PCOS: Does low-grade chronic inflammation in PCOS relate to PCOS itself or obesity? Arch Gynecol Obstet 2012; 286: 1065-1071

[44] Quinn M, Shinkai K, Pasch L, Kuzmich L, Cedars M, Huddleston H. Prevalence of androgenic alopecia in patients with polycystic ovary syndrome and characterization of associated clinical and biochemical features. Fertil Steril 2014; 101: 1129-1134

[45] Göbl CS, Ott ], Bozkurt L, Feichtinger M, Rehmann V, Cserjan A, Heinisch M, Steinbrecher H, JustKukurova I, Tuskova R. To assess the association between glucose metabolism and ectopic lipid content in different clinical classifications of PCOS. PloS One 2016; 11: e0160571

[46] Hahn S, Janssen OE, Tan S, Pleger K, Mann K, Schedlowski M, Kimmig R, Benson S, Balamitsa E, Elsenbruch S. Clinical and psychological correlates of quality-of-life in polycystic ovary syndrome. Eur J Endocrinol 2005; 153: 853-860
[47] Chae SJ, Kim J], Choi YM, Hwang KR, Jee BC, Ku SY, Suh CS, Kim SH, Kim JG, Moon SY. Clinical and biochemical characteristics of polycystic ovary syndrome in Korean women. Human Reprod. 2008; 23 : 1924-1931

[48] Misichronis G, Georgopoulos N, Marioli D, Armeni A, Katsikis I, Piouka A, Saltamavros A, Roupas N, Panidis D. The influence of obesity on androstenedione to testosterone ratio in women with polycystic ovary syndrome (PCOS) and hyperandrogenemia. Gynecol Endocrinol 2012; 28: $249-252$

[49] Amato MC, Galluzzo A, Merlino S, Mattina A, Richiusa P, Criscimanna A, Giordano C. Lower insulin sensitivity differentiates hirsute from non-hirsute Sicilian women with polycystic ovary syndrome. Eur J Endocrinol 2006; 155: 859-865

[50] Adali E, Yildizhan R, Kurdoglu M, Kolusari A, Edirne T, Sahin H, Yildizhan B, Kamaci M. The relationship between clinico-biochemical characteristics and psychiatric distress in young women with polycystic ovary syndrome. J Int Med Res 2008; 36: 1188-1196

[51] Liang S-J, Hsu C-S, Tzeng C-R, Chen C-H, Hsu M-I. Clinical and biochemical presentation of polycystic ovary syndrome in women between the ages of 20 and 40. Human Reprod 2011; 26: 3443-3449

[52] Katulski K, Czyzyk A, Podkowa N, Podfigurna-Stopa A, Ignaszak N, Paczkowska K, Slawek S, Szpurek D, Meczekalski B. Clinical and hormonal features of women with polycystic ovary syndrome living in rural and urban areas. Ann Agric Environ Med 2017; 24: 522-526

[53] Wijeyaratne CN, Balen AH, Barth JH, Belchetz PE. Clinical manifestations and insulin resistance (IR) in polycystic ovary syndrome (PCOS) among South Asians and Caucasians: Is there a difference? Clin Endocrinol 2002; 57: 343-350

[54] Chanukvadze D, Kristesashvili ], Kvashilava N. Correlation of biochemical markers and clinical signs of hyperandrogenism in women with polycystic ovary syndrome (PCOS) and women with non-classic congenital adrenal hyperplasia (NCAH). Iran J Reprod Med 2012; 10: 307

[55] Rosenfield RL. Ovarian and adrenal function in polycystic ovary syndrome. Endocrinol Metab Clin North Am 1999; 28: 265-293

[56] Li L, Yang D, Chen X, Chen Y, Feng S, Wang L. Clinical and metabolic features of polycystic ovary syndrome. Int J Gynecol Obstet 2007; 97: 129-134

[57] Gambineri A, Pelusi C, Vicennati V, Pagotto U, Pasquali R. Obesity and the polycystic ovary syndrome. Int J Obes Relat Metab Disord 2002; 26: 883-896

[58] Escobar-Morreale H, Carmina E, Dewailly D, Gambineri A, Kelestimur F, Moghetti P, Pugeat M, Qiao J, Wijeyaratne C, Witchel S. Epidemiology, diagnosis and management of hirsutism: A consensus statement by the Androgen Excess and Polycystic Ovary Syndrome Society. Human Reprod Update 2012; 18: 146-170

[59] Carmina E, Guastella E, Longo RA. Advances in the diagnosis and treatment of PCOS. Curr Pharmaceut Des 2016; 22: 5508-5514

[60] Lo JC, Feigenbaum SL, Yang J, Pressman AR, Selby JV, Go AS. Epidemiology and adverse cardiovascular risk profile of diagnosed polycystic ovary syndrome. J Clin Endocrinol Metab 2006; 91: 1357-1363

[61] Tehrani FR, Montazeri SA, Hosseinpanah F, Cheraghi L, Erfani H, Tohidi $\mathrm{M}$, Azizi F. Trend of cardio-metabolic risk factors in polycystic ovary syndrome: A population-based prospective cohort study. PloS One 2015; 10: e0137609

[62] Teede H, Deeks A, Moran L. Polycystic ovary syndrome: A complex condition with psychological, reproductive and metabolic manifestations that impacts on health across the lifespan. BMC Med 2010; 8: 41

[63] Morales A, Laughlin G, Bützow T, Maheshwari H, Baumann G, Yen S. Insulin, somatotropic, and luteinizing hormone axes in lean and obese women with polycystic ovary syndrome: Common and distinct features. J Clin Endocrinol Metab 1996; 81: 2854-2864 
[64] Cataldo NA. Insulin-like growth factor binding proteins: Do they play a role in polycystic ovary syndrome? Seminars in reproductive endocrinology. Stuttgart: Thieme Medical Publishers, Inc.; 1997

[65] Tsilchorozidou T, Overton C, Conway GS. The pathophysiology of polycystic ovary syndrome. Clin Endocrinol 2004; 60: 1-17

[66] El-Mazny A, Abou-Salem N, El-Sherbiny W, El-Mazny A. Insulin resistance, dyslipidemia, and metabolic syndrome in women with polycystic ovary syndrome. Int J Gynecol Obstet 2010; 109: 239-241

[67] Liang S], Liou TH, Lin HW, Hsu CS, Tzeng CR, Hsu MI. Obesity is the predominant predictor of impaired glucose tolerance and metabolic disturbance in polycystic ovary syndrome. Acta Obstet Gynecol Scand 2012; 91: 1167-1172

[68] Rehme MFB, Pontes AG, Corrente JE, Franco JG Jr., Pontes A. Contribution of hyperandrogenism to the development of metabolic syndrome in obese women with polycystic ovary syndrome. Rev Brasil Ginecol Obstet 2013; 35: 562-568
[69] Yildiz BO, Bolour S, Woods K, Moore A, Azziz R. Visually scoring hirsutism. Human Reprod Update 2010; 16: 51-64

[70] Carmina E. Ovarian and adrenal hyperandrogenism. Ann New York Acad Sci 2006; 1092: 130-137

[71] Škrha J, Haas Ts, Šindelka G, Prázný M, Widimský Ji, Cibula D, Svačina S. Comparison of the insulin action parameters from hyperinsulinemic clamps with homeostasis model assessment and QUICKI indexes in subjects with different endocrine disorders. J Clin Endocrinol Metab 2004; 89: 135-141

[72] Lawson MA, Jain S, Sun S, Patel K, Malcolm PJ, Chang RJ. Evidence for insulin suppression of baseline luteinizing hormone in women with polycystic ovarian syndrome and normal women. J Clin Endocrinol Metab 2008; 93: 2089-2096 